\title{
SISTEM PERINGATAN DINI KEBAKARAN HUTAN MENGGUNAKAN MODUL NODEMCU DAN BOT TELEGRAM DENGAN KONSEP INTERNET OF THINGS (IOT)
}

\author{
Mohamad Jamil ${ }^{1}$, Hafid Saefudin², Sarby Marasabessy ${ }^{3}$ \\ ${ }^{1,3}$ Teknik Informatika, Universitas Khairun, ${ }^{2}$ Teknik Elektro,Universitas Khairun, Ternate, Indonesia \\ Email: ${ }^{1}$ jamil@unkhair.ac.id, ${ }^{2}$ hafid@unkhair.ac.id, ${ }^{3}$ sarby@unkhair.ac.id
}

\begin{abstract}
Abstrak
Hutan mempunyai peranan yang penting bagi kehidupan makhluk hidup. Saat ini kebakaran hutan (Karhutla) menjadi masalah serius yang dapat mengganggu simbiosis dan rantai kehidupan makhluk hidup. Permasalahan ini sudah menjadi perhatian bagi masyarakat, pemerintah maupun dunia. Data yang diperoleh hingga Agustus 2019 tercatat 328.724 Hektare dan lahan hutan terbakar. Untuk mengatasi permasalahan tersebut, pemerintah melakukan berbagai usaha baik berupa himbauan maupun sanksi hukum terhadap suatu tindakan yang mengancam kelestarian hutan baik yang dilakukan secara individu atau kelompok Banyak kasus kebakaran hutan diketahui pada saat sudah terjadi kebakaran dan sedikit dapat dideteksi lebih awal. Informasi terjadinya kebakaran banyak didapat oleh warga sekitar lokasi kebakaran. Untuk mendapatkan bantuan pihak pemadam kebakaran maka di perlukan peran serta masyarakat, untuk menghubungi pihak pemadam kebakaran agar dapat mengantisipasi secara dini bencana kebakaran. Tujun dari p enelitian ini yaitu melakukan pengembangan sistem peringatan dini kebakaran hutan menggunakan modul nodemcu dan BOT Telegram dengan konsep Internet Of Things (IOT). Berdasarkan hasil pengujian Sistem peringatan dini kebakaran Hutan dengan menggunakan modul Nodemcu dan BOT Telegram dengan konsep Internet Of Things (IOT) ini sangat membantu memberikan informasi yang cepat untuk mengetahui kebakaran yang terjadi di hutan, dengan menggunakan metode Internet Of Things maka petugas akan mampu mengetahui kondisi secara real time, di karenakan teknologi ini mampu memonitoring hardware menggunakan sarana komunikasi internet berupa Telegram sehingga jarak dan lokasi tidak terpengaruh asal kan sensor yang di pakai mendeteksi perubahan yang terjadi.
\end{abstract}

Kata kunci: Internet Of Things, Nodemcu, Telegram, Thingspeak, Kebakaran Hutan

\begin{abstract}
Forests have an important role in the life of living things. Nowadays forest fires (Karhutla) become a serious problem that can disrupt the symbiosis and life chain of living things. This problem has become a concern for the community, government and the world. Data obtained until August 2019 recorded 328,724 hectares and burned forest land. To overcome this problem, the government has made various efforts in the form of appeals or legal sanctions on actions that threaten forest sustainability whether carried out individually or in groups. Many cases of forest fires are known when a fire has occurred and little can be detected early. Information on the occurrence of many fires was obtained by residents around the location of the fire. To get the help of the fire department, community participation is needed, to contact the fire department so that they can anticipate the fire disaster early. The aim of this research is to develop a forest fire early warning system using the nodemcu module and the Telegram BOT with the Internet of Things (IOT) concept. Based on the test results of the Forest Fire early warning system using the Nodemcu module and the Telegram BOT with the concept of the Internet of Things (IOT) it is very helpful to provide quick information to find out fires that occur in the forest, by using the Internet of Things method, the officer will be able to know the conditions in real time, because this technology is capable of monitoring hardware using internet communication tools such as Telegram so that distance and location are not affected as long as the sensor used detects changes that occur.
\end{abstract}

Keywords: Internet Of Things, Nodemcu, Telegram, Thingspeak, Forest fires

\section{PENDAHULUAN}

Hutan mempunyai peranan yang penting bagi kehidupan makhluk hidup. Saat ini kebakaran hutan (Karhutla) menjadi masalah serius yang dapat mengganggu simbiosis dan rantai kehidupan makhluk hidup. Permasalahan ini sudah menjadi perhatian bagi masyarakat, pemerintah maupun dunia. Fenomena ini sering terjadi setiap tahun sering diakibakan oleh faktor alam dan 99\% ulah dari manusia itu sendiri [1] Data yang diperoleh hingga Agustus 2019 tercatat 328.724 Hektare dan lahan hutan terbakar. Untuk mengatasi permasalahan tersebut, pemerintah melakukan berbagai usaha baik berupa himbauan maupun sanksi hukum terhadap suatu tindakan yang mengancam kelestarian hutan baik yang dilakukan secara individu atau kelompok. namun usaha yang telah dilakukan pemerintah tersebut masih belum efektif, dimana tingkat kelestarian hutan masih menunjukkan angka yang cukup memprihatinkan. Badan Meteorologi Klimatologi dan Geofisika (BMKG), Lembaga Penerbangan dan Antariksa Nasional (LAPAN), dan Badan Pengkajian dan Penerapan Teknologi (BPPT) merupakan instansi yang bertanggung jawab dalam manajemen pengendalian kebakaran hutan [2] Data dan informasi yang dihasilkan oleh instansi pemerintah ini diperlukan dalam upaya pencegahan, terutama dalam kegiatan peringatan dini terjadinya kebakaran hutan. Sistem peringatan dini karhutla sangat penting untuk memberikan warning dan menghindari bencana lainnya yang diakibatkan oleh karhutla. Sistem dimaksudkan supaya masyarakat dan pihak terkait mendapat informasi lebih awal terkait karhutla [3] Banyak kasus kebakaran hutan diketahui pada saat sudah terjadi kebakaran dan sedikit dapat dideteksi lebih awal. Informasi terjadinya kebakaran banyak didapat oleh warga sekitar lokasi kebakaran. Untuk mendapatkan bantuan pihak pemadam kebakaran maka di perlukan peran serta masyarakat, untuk menghubungi pihak pemadam kebakaran agar dapat mengantisipasi bencana kebakaran tersebut, informasi berbasis masyarakat seperti ini merupakan model konvensional yang sering dilakukan saat ini, cara ini mempunyai kelemahan dimana diperlukan waktu dalam proses informasi kepihak Pemadam Kebakaran. Oleh karena itu maka dibutuhkan sebuah sistem yang mampu memberikan 
informasi secara dini terkait kebakaran hutan atau lahan (karhutla) kepada pihak-pihak terkait agar dapat dengan mudah di tindaklanjuti. Penelitian ini akan coba melakukan pengembangan sistem peringatan dini kebakaran hutan menggunakan modul nodemcu dengan konsep Internet Of Things (IoT). Beberapa penelitian telah banyak membahas sistem peringatan dini bahaya kebakaran hutan, diantaranya dengan memanfaatkan IOT dan SMS Gateway [4], Simulasi Alat pendeteksi Kebakaran Sensor asap MQ2 dan Sensor Suhu LM35 Berbasis Arduino [5]. Dari beberapa penelitian tersebut maka fokus penelitian ini yaitu lebih dititik beratkan pada jenis media komunikasi dan juga modul yang akan digunakan untuk mempercepat proses pengiriman data ke pengguna sebagai infomasi dini kebakaran yang terjadi.

\section{TEORITIS}

\subsection{Internet Of Things (IoT)}

Internet of Things (IoT) pertama kali diperkenalkan oleh Kevin Ashton pada tahun 1999. Meski telah diperkenalkan sejak 15 tahun yang lalu, hingga kini belum ada sebuah konsensus global mengenai definisi IoT. Namun secara umum konsep IoT diartikan sebagai sebuah kemampuan untuk menghubungkan objek-obek cerdas dan memungkinkannya untuk berinteraksi dengan objek lain, lingkungan maupun dengan peralatan komputasi cerdas lainnya melalui jaringan internet. IoT dalam berbagai bentuknya telah mulai diaplikasikan pada banyak aspek kehidupan manusia. Contohnya bahan pangan, elektronik, koleksi, peralatan apa saja, termasuk benda hidup yang semuanya tersambung ke jaringan lokal dan global melalui sensor yang tertanam dan selalu aktif.

Salah satu tantangan yang harus diatasi untuk mendorong implementasi IoT secara luas adalah faktor keamanan. IoT merupakan sebuah sistem yang majemuk. Kemajemukannya bukan hanya karena keterlibatan berbagai entitas seperti data, mesin, RFID, sensor dan lain-lain, tetapi juga karena melibatkan berbagai peralatan dengan kemampuan komunikasi dan pengolahan data. Banyaknya entitas dan data yang terlibat, membuat IoT menghadapi resiko keamanan yang dapat mengancam dan membahayakan konsumen. Ancaman ini utamanya dilakukan dengan cara memungkinkan orang yang tidak berhak untuk mengkases data dan menyalah gunakan informasi personal, memfasilitasi serangan terhadap sistem yang lain, serta mengancam keselamatan personal penggunanya [6]

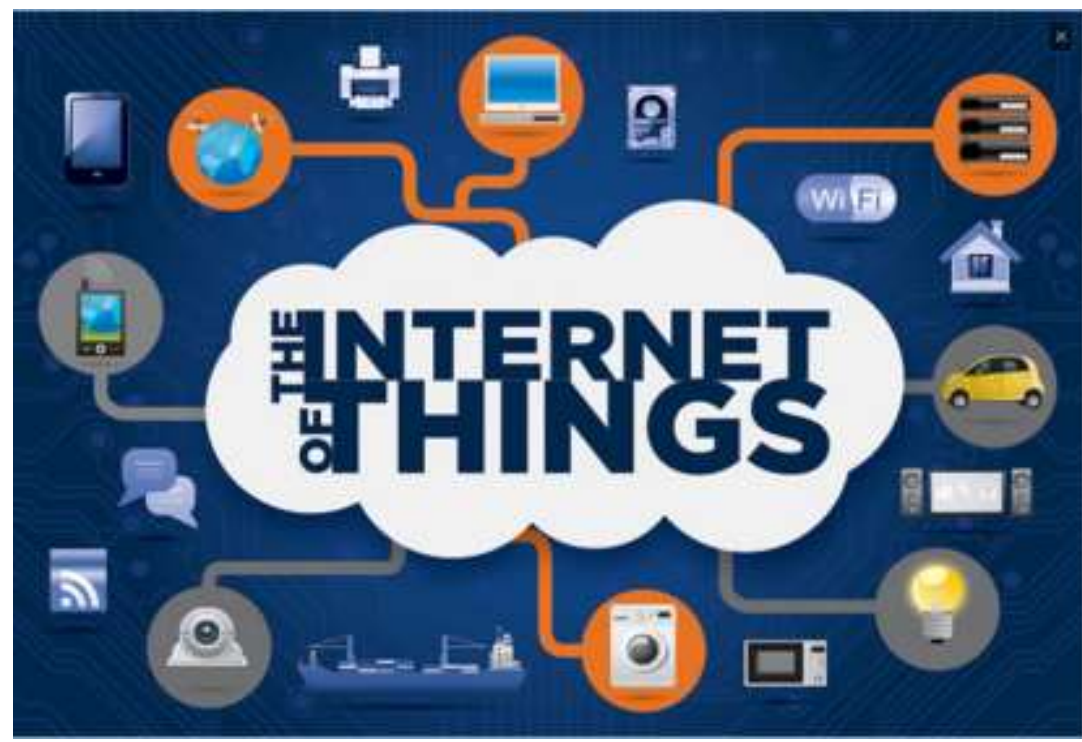

Gambar 1. Internet Of Things (IoT) [6]

\section{ANALISA DAN PEMBAHASAN}

Pengembangan Sistem Peringatan dini kebakaran Hutan didesain dengan menggunakan metode prototype yang terdiri dari : Analisis Kebutuhan, Desain Sistem, Pengkodean (Coding), Pengujian dan Implementasi.

1. Tahapan Analisis Kebutuhan Sistem

Analisis Kebutuhan sistem mempunyai tujuan untuk menganalisis dan mengidentifikasi permasalahan sehingga menghasilkan suatu ide dan gagasan serta konsep awal perancangan sistem. Tabel berikut menunjukan kebutuhan perangkat keras dan perangkat lunak sistem

Tabel 1. Spesifikasi Kebutuhan Perangkat Keras dan Perangkat Lunak Sistem

\begin{tabular}{ccc}
\hline No & Perangkat Keras & Perangkat Lunak \\
\hline 1 & Laptop dengan Spesifikasi Sistem Operasi Windows 10 64 BIT & Arduino Ide 1.8 \\
2 & Processor Clock Speed 2.4 Ghz & Mozila Firefox/Chrome \\
3 & Harddrive 500GB & Microsoft Visio \\
4 & RAM 4GB & Thingspeak
\end{tabular}




\begin{tabular}{lcc}
5 & Layar Monitor dengan Resolusi 1366x 768 Px & Telegram \\
6 & Modul Nodemcu & \\
7 & Sensor Suhu DHT21 & \\
8 & Sensor Asap MQ-2 & \\
\hline
\end{tabular}

2. Tahapan Desain Sistem

Tahapan ini mempunyai tujuan untuk memenuhi kebutuhan pengguna untuk pengembangan sistem peringatan dini kebakaran hutan. Mka dibuatlah rancangan sistem dalam bentuk diagram blok seperti ditunjukan pada gambar 2:

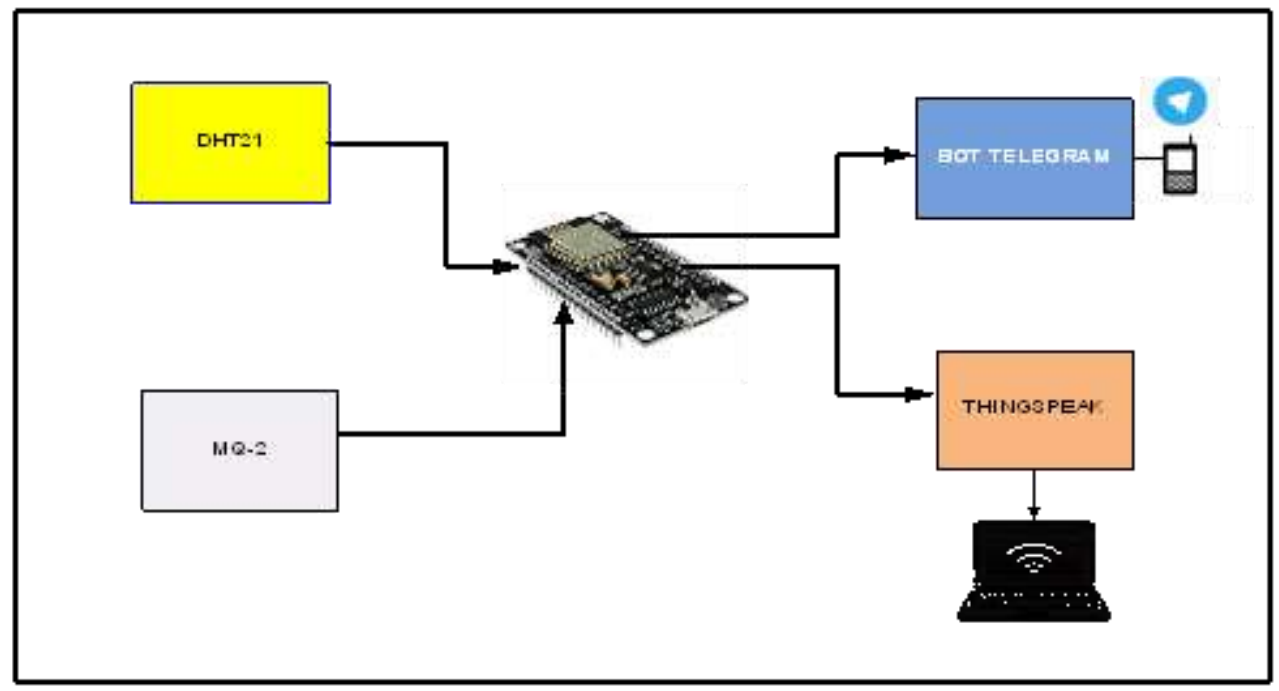

Gambar 2. Blok Diagram Sistem

Berdasarkan blok diagram yang dibuat dapat dijelaskan Prinsip kerja dari sistem sebagai berikut:

sensor suhu akan menampilkan nilai temperature secara real-time pada komputer/laptop yang berada pada pos sebagai acuan keadaan hutan, yang pertama adalah jika suhu antara <40 C dan Nilai Asap >100 PPM maka status yang terkirim via telegram adalah Waspada, sedangkan jika suhu >40 dan Nilai asap >500 PPM maka status Bahaya. Nilai yang terbaca dan terkirim akan selalu terupdate dan dapat dimonitoring melalui aplikasi Thingspeak

3. Tahapan Pengkodean (Coding)

Tahapan ini merupkan tahapan dimana sebuah perangkat lunak dibangun sesuai dengan kebutuhan pengguna. Dalam kasus ini program yang dibuat menggunakan perangkat lunak Arduino IDE. Berikut penggalan script dari system

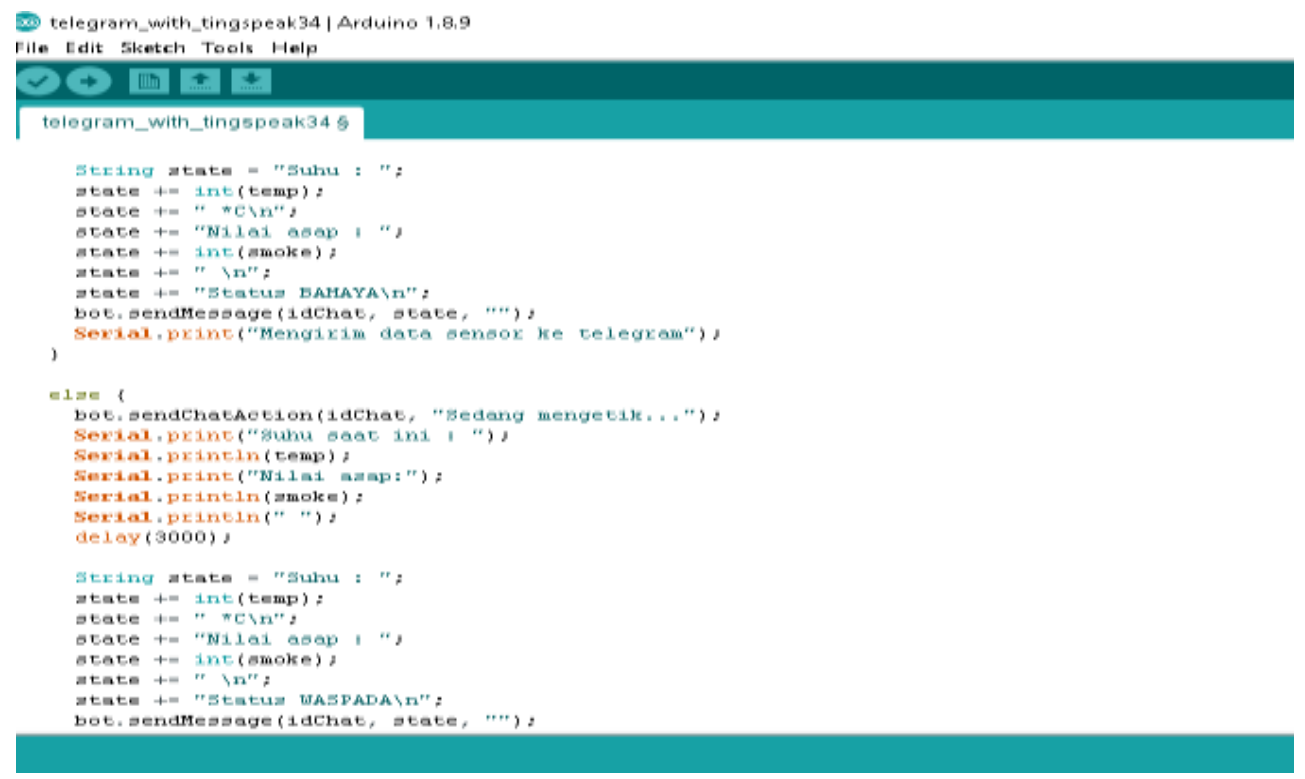

Gambar 3. Penggalan Script Sistem Peringatan dini Kebakaran

4. Tahapan Pengujian dan Implementasi 
Tahapan ini bertujuan untuk menguji fungsionalitas dari rancangan sistem yang telah dibuat, dalam kasus ini perencanaan pengujian diawali dengan sebuah wadah yg didalamnya terdapat benda yang dapat dibakar, alat yang sudah dibuat di tempatkan di atas wadah tersebut, dalam sebuah alat terdapat SensorMQ-2 yang mana berfungsi sebagai pendeteksi asap apidan Sensor DHT 21 yang mana berfungsi sebagai pendeteksi suhu panas yang berasal dari api tersebut.
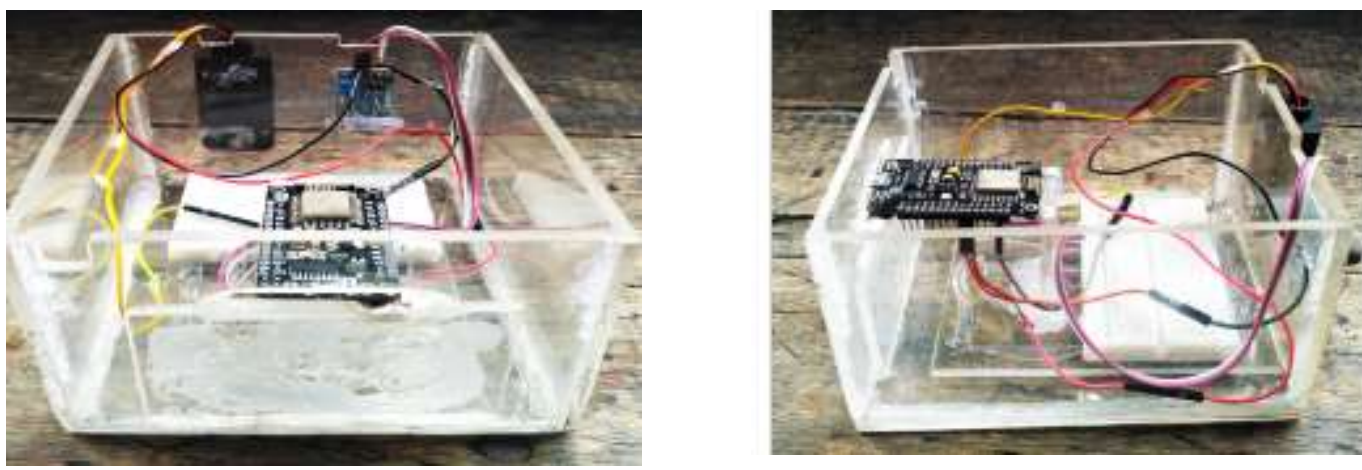

Gambar 4. Perangkat Sistem Peringatan Dini

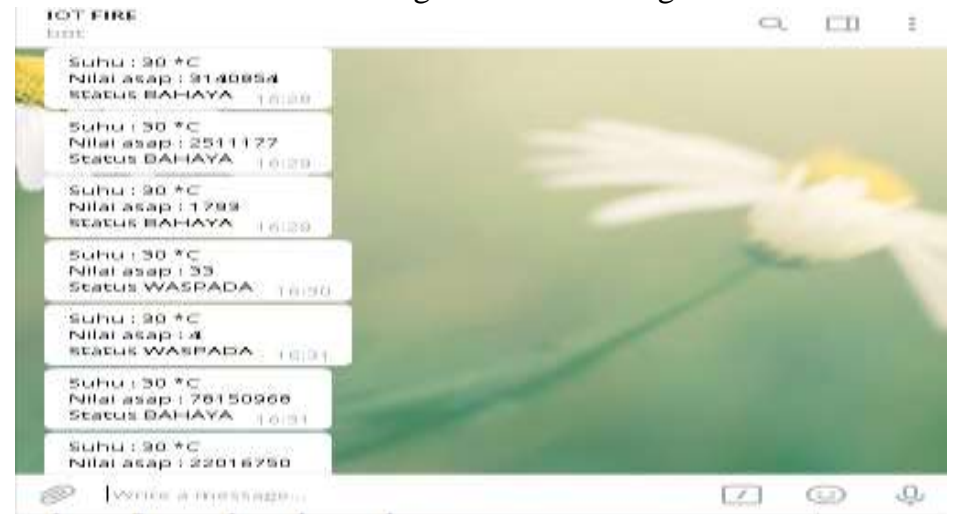

Gambar 5 . Hasil Pengujian Sistem Dengan Telegram

IOT KEBAKARAN HUTAN

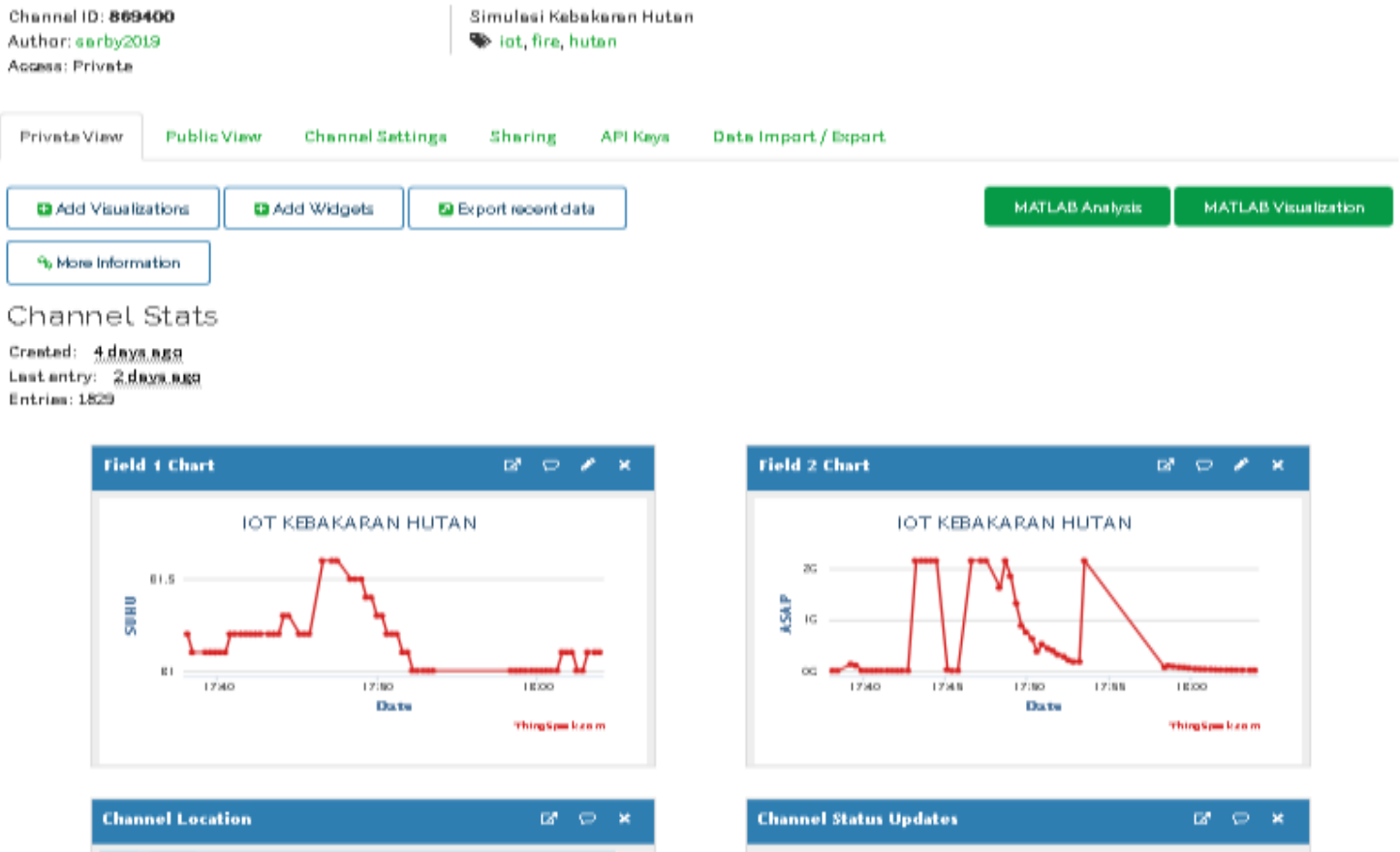

Gambar 6. Hasil Pengujian Sistem Dengan Thingspeak

\section{KESIMPULAN}


Berdasarkan hasil pengujian Sistem peringatan dini kebakaran Hutan dengan menggunakan modul Nodemcu dan BOT Telegram dengan konsep Internet Of Things (IOT) ini sangat membantu memberikan informasi yang cepat untuk mengetahui kebakaran yang terjadi di hutan, dengan menggunakan metode Internet Of Things maka petugas akan mampu mengetahui kondisi secara real time, di karenakan teknologi ini mampu memonitoring hardware menggunakan sarana komunikasi internet berupa Telegram sehingga jarak dan lokasi tidak terpengaruh asal kan sensor yang di pakai mendeteksi perubahan yang terjadi. Hasil pengujian yang telah di lakukan menghasil kan beberapa kesimpulan antara lain:

1. Sensor Suhu DHT 21 mampu mendeteksi suhu yang hampir mirip dengan kondisi nyata di lapangan

2. Sensor Asap MQ-2 mampu mendeteksi kadar asap dengan range 100-500 PPM, namun kondisi ini sangat dipengaruhi oleh arah angin

3. Proses Pengujian pengiriman data antara peragkat dengen telegram dan Thngspeak dapat berlangsung dengan baik tanpa mengalami kendala

\section{REFERENCES}

[1] AHAMAD FAJAR. Sinergitas Instansi Pemerintah daerah dalam penanggulangan kebakaran hutan dan lahan di Kabupaten Okan hilir Propinsi Riau Pada Tahun 2015. Skripsi. Universitas Riau. 2015.

[2] MARgareta C, \& NUGROHO AGUNG, H. Prototipe Sistem Peringatan Dini Kebakaran Hutan Berbasis Parameter Cuaca. Wahana Fisika. Vol 2 Nomor 2. 2017.

[3] BADRI MUHAMMAD, LUBIS P DJUARA, JOKO SUSANTO \& SUHARJITO DIDIK. Sistem Komunikasi dini Pencegahan Kebakaran Hutan dan Lahan di Provinsi Riau. Jurnal PIKOM Vol 19 Nomor 1 Juni 2018.

[4] MAHENDRA ARIE. Rancang bangun Sistem Pendeteksi Kebakaran Berbasis IoT dan SMS Gateway menggunakan Arduino. Jurnal Simetris Vol 8 Nomor 2. 2017.

[5] ROHIM N FAISOL. NILOGIRI A. RUSGIANTO. Simulasi alat Pendeteksi Kebakaran Menggunakan Sensor Asap MQ2, Sensor Suhu LM35, Dan Modul WIFI ESP 8266 Berbasis Mikrokontroler Arduino. Skripsi. Universitas Muhammadiyah Jember.

[6] YASHA. Mengenal Internet Of Things: Pandua Lengkap. 2018. Diakses melalui laman: https://www.dewaweb.com/blog/internet-of-things/ 